\title{
BODY MASS INDEX IN PATIENTS WITH SYSTEMIC AUTOIMMUNE MYOPATHIES ASSISTED AT A TERTIARY HOSPITAL: A CROSS-SECTIONAL STUDY
}

Clarice Alves Esmeraldo ${ }^{1}$, Amália Maria Fernandes de Sá Duarte Filha ${ }^{1}$, Carolina Dias da Silva Amorim¹, Andrea Tavares Dantas ${ }^{1}$, Angela Luzia Branco Pinto Duarte ${ }^{1}$, Laurindo Ferreira da Rocha Junior ${ }^{1, \star}$

1.Universidade Federal de Pernambuco, Recife (PE), Brazil.

*Corresponding author: laurindorochajr@hotmail.com

\section{BACKGROUND}

Systemic autoimmune myopathies (SAM) are heterogeneous diseases in which muscle inflammation is a hallmark. Prevalence of obesity has increased worldwide and is an issue of public health. Few studies have evaluated the frequency of obesity and overweight in patients with SAM. This study aimed to determine the presence of obesity or overweight in patients with SAM followed in an outpatient rheumatology clinic at a tertiary hospital in the state of Pernambuco.

\section{METHODS}

Descriptive cross-sectional study with patients with SAM assisted at Hospital das Clínicas da Universidade Federal de Pernambuco. Patients fulfilled classification criteria for SAM and werefollowed between May 2020 and June2021. Demographic and clinical characteristics, such as weight and height were collected during visit consultations and by medical record reviews or telephone interview (Table 1). Body mass index (BMI) was calculated and patients were classified according to values as underweight $<18.5 \mathrm{~kg} / \mathrm{m}^{2}$, normal weight $\geq 18.5$ to $24.9 \mathrm{~kg} / \mathrm{m}^{2}$, overweight $\geq 25.0$ to $29.9 \mathrm{~kg} / \mathrm{m}^{2}$ and obese $\geq 30 \mathrm{~kg} / \mathrm{m}^{2}$. Statistical analysis was performed.

Table 1. Characteristics and Body mass index presentation of the patients with systemic autoimmune myopathies.

\begin{tabular}{lc}
\hline Characteristic & 47 \\
\hline Number of patients & $49.5(19-71)$ \\
\hline Age, years, mean (range) & $5(0.4-29)$ \\
\hline Disease duration, years, median (range) & $37 / 10$ \\
\hline Female/male & $2(4.2)$ \\
\hline Body mass index (\%) & $14(29.7)$ \\
\hline Underweight & $19(40.4)$ \\
\hline Normal & $12(25.6)$ \\
\hline Overweight & \\
\hline Obesity & 46.5 \\
\hline Average weight (kg) & 59.7 \\
\hline Underweight & 70.9 \\
\hline Normal & 88.1 \\
\hline Overweight
\end{tabular}

\section{RESULTS}

Fifty-four patients were followed during the period of the study but seven patients were excluded of the analysis due to lack of values of height or weight. The mean age of the 47 patients included was $49.5( \pm 13.4)$ years. Most of the patients were females $(n=37,78.7 \%)$, being dermatomyositis the most frequent myopathy (49\%). Two (4.35\%) patients were considered underweight, 14 (29.8\%) normal weight, 19 (40.4\%) overweight and 12 (25.5\%) were obese (Table 1). The BMI value correlated negatively with

Realização: 
corticosteroid dose $(r=-0.3800, p=0.0084)$. The median corticosteroid dose was higher in normal and underweight patients compared to patients with $B M I \geq 25.0$, with values of 20 (IQR 1.5-40.0) $\mathrm{mg}$ and 5 (IQR 0.0-15.0) mg, respectively ( $p=0.0269)$. The proportion of patients with fibromyalgia (33\%) in obese patients was significantly higher than non-obese patients ( $3 \%), p=0.0118$. These patients $(n=5)$ have significantly higher BMI $32.6( \pm 6.3) \mathrm{kg} / \mathrm{m}^{2}$ than not patients with fibromyalgia BMI 26.6 $( \pm 4.6) \mathrm{kg} / \mathrm{m}^{2}$ $(p=0.01)$. Amyopathic dermatomyositis was more frequent $(33 \%)$ in patients with normal and underweight $(p=0.0396)$.

\section{CONCLUSION}

Overweight and obesity were frequent in our sample. Patients with higher BMI use minor corticosteroids dose and this finding may reflect a concern of the assistant physician in prescribing lower doses of these drugs to this group as these patients may gain weight with higher doses. Although the number of patients with fibromyalgia was low there was an association of this condition with obesity.

\section{KEYWORDS}

Myositis, Obesity, Body mass index, Overweight, Fibromyalgia. 